\title{
Laboreal
}

Volume $14 \mathrm{~N}^{\circ} 2$ | 2018

Digitalização e evolução do trabalho real

\section{Compreender a atividade de conceção e o seu desenvolvimento}

Comprender la actividad de diseño y su desarrollo

Comprendre l'activité de conception et son développement

Understanding the design activity and its development

\section{Annie Weill-Fassina}

Tradutor. João Viana Jorge

\section{OpenEdition}

\section{Journals}

\section{Edição electrónica}

URL: http://journals.openedition.org/laboreal/706

DOI: $10.4000 /$ laboreal. 706

ISSN: 1646-5237

\section{Editora}

Universidade do Porto

\section{Refêrencia eletrónica}

Annie Weill-Fassina, «Compreender a atividade de conceção e o seu desenvolvimento », Laboreal [Online], Volume $14 \mathrm{~N}^{0} 2$ | 2018, posto online no dia 01 dezembro 2018, consultado o 24 setembro 2020. URL : http://journals.openedition.org/laboreal/706 ; DOI : https://doi.org/10.4000/laboreal.706

Este documento foi criado de forma automática no dia 24 setembro 2020.

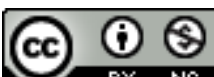

Laboreal está licenciado com uma Licença Creative Commons - Atribuição-NãoComercial 4.0 Internacional. 


\title{
Compreender a atividade de conceção e o seu desenvolvimento
}

\author{
Comprender la actividad de diseño y su desarrollo \\ Comprendre l'activité de conception et son développement \\ Understanding the design activity and its development
}

\section{Annie Weill-Fassina}

Tradução : João Viana Jorge

\section{REFERÊNCIA}

Comentário ao texto de Lebahar, J.-Ch. (2007). La conception en design industriel et en architecture. Désir, pertinence, coopération et cognition (pp. 15-21). Paris: HermesLavoisier.

\section{NOTA DO EDITOR}

http://dx.doi.org/10.15667/laborealxiv218awfpt

Manuscrito recebido em: junho/2018

Aceite após peritagem: setembro/2018

1 Na introdução do livro, 'La conception en design industriel et en architecture' 'publicado em 2007, Jean-Charles Lebahar especifica como perspetiva a conceção: 'a atividade de conceção é a construção e a comunicação de um modelo de artefacto que não resulta da réplica de um modelo (pré)existente' (p.15), devendo a elaboração deste modelo permitir a realização do artefacto por aqueles que terão a seu cargo o seu fabrico. Também especifica a sua intenção: 'As análise de atividade recolhidas neste livro sob a forma de estudos de caso estão centradas num sujeito psicológico que concebe artefactos (ou seja) 'um sujeito concetor' (idem, p.15). Na situação de conceção intervêm em simultâneo as caraterísticas do sujeito concetor e as da tarefa 
(constrangimentos técnicos e operacionais). 'A abordagem pluridisciplinar permite definir a atividade do sujeito concetor sob um ângulo em simultâneo cognitivo $\mathrm{e}$ semiológico' (p. 18).

\section{A conceção não é uma resolução de um problema mal definido}

2 Mesmo não sendo ele próprio a produzir o artefacto, o concetor deve conhecer e integrar no seu modelo as técnicas e constrangimentos de fabrico ou de construção para que a realização se torne possível. Do ponto de vista cognitivo constata-se pois desde o início do processo de conceção que, para o concetor, (como é aliás frequente em ergonomia) se trata mais de construir uma representação da situação de conceção que deverá transformar do que apenas colocar e resolver um problema mal definido.

Desta análise, Lebahar conclui que a conceção não é identificável com uma resolução de problema. Para ele as diferenças encontram fundamento em diversas constatações:

4 A formulação do problema e por conseguinte a tarefa de conceção evolui de forma imprevista no decurso da atividade o que dá a (essa) atividade um andamento oportunista;

5 A situação de conceção não consiste num só problema mas em diversos problemas de múltiplos formatos e múltiplos domínios que requerem uma articulação entre eles;

6 A atividade não é redutível a um código único de ações e operações como numa demonstração matemática ou em procedimentos como é o caso da 'torre de Hanói' ou do 'jogo de Marienbad';

7 Os procedimentos, tanto quanto os resultados, variam de um concetor a outro;

8 As soluções escolhidas são consideradas satisfatórias em relação a um dado número de critérios mas raramente estão otimizadas.

9 Segundo o autor,

'pode-se optar por uma redução da situação a uma resolução de problema mal definido efetuada por um sistema de tratamento da informação. Pode-se, ao contrário, como é aqui o caso, considerar que uma tarefa de conceção se situa numa envolvente histórica de constrangimentos e de recursos e que essa tarefa se realiza através de uma competência bem mais complexa que um simples sistema de tratamento da informação. A competência de conceção não pode reduzir-se a um autómato informático cujas operações obedecem às simples regras e definições de um código de interpretação dos comportamentos humanos aplicáveis a priori e indiferentemente a tarefas tão complexas como a conceção de uma carroceria de automóvel, de um edifício ou de uma lanterna de bolso. A competência de um sujeito concetor comporta, sem a isso se reduzir, um sistema de tratamento da informação. Mas essa competência é também feita de sistemas de valores, de crenças e de significados que estão na origem das hipóteses de conceção que o sujeito elabora ou que toma de empréstimo a outras pessoas' (2007 p.32).

10 Se o trabalho de conceção pode levar a pensar no trabalho de criação, dele se diferencia em numerosos aspetos. 


\section{Conceção e criação, atividades diferentes}

11 Respeitante às relações entre conceção e criatividade, Lebahar afirma claramente que 'o sujeito concetor não poderia realizar a sua tarefa se se encontrasse num deserto social e técnico, contrariamente à mitologia do ato criador'. De facto, a descrição da conceção arquitetural e dos processos de design industrial não assenta 'numa cadeia de reações totalmente subjectivas. A luta pela realização é uma série de esforços, de dores, de satisfações, de recusas, de decisões que não podem nem devem ser plenamente conscientes, pelo menos no plano estético' (2007 p. 30).

12 Se a evolução das representações pode fazer pensar por instantes num ato criador, as análises sublinham-lhe caraterísticas específicas:

- um objeto comandado do exterior;

- um objetivo não apenas estético mas também funcional e securitário;

- a ausência de criação ex-nihilo;

- a dependência ou a submissão a constrangimentos aos quais é preciso responder

13

Esta diferenciação do 'ato criador' não diz ainda nada da 'criatividade' do concetor. Pode definir-se a criatividade como 'a capacidade de um indivíduo ou de um grupo de imaginar ou construir e por em prática um conceito novo, um objeto novo ou de descobrir uma solução original de um problema's. A este nível muito global, não se pode negar que a noção de criatividade, mesmo que não se saiba nem 'avaliá-la' nem 'medi-la', possa aplicar-se a determinados concetores em arquitetura ou em design em virtude da originalidade dos seus projetos ou da sua realização. Mas o imaginário não tem a mesma função na conceção e na arte. Como nota Lebahar numa das suas obras precedentes,

'a criação em arte não é comparável às outras atividades humanas de conceção mesmo que

se trate de criar objetos artificiais que fascinem os seus espetadores. 0 imaginário e $o$

fantasma são os seus motores evidentes mas fornecem essencialmente a estas démarches, energias e estilos que, sob a forma de desejos e de esquemas modelam o valor de uso. Em arte,

o imaginário e o fantasma são maneiras de ver o mundo que incluem também a de se ver a a

si próprio e de se mostrar ao outro.' (1998 p.12-13).

É por isso que além destas primeiras definições, «o processo criativo e o processo de conceção» não podem ser assimilados. Em geral o processo criativo é definido como 'um processo mental implicando a geração de novas ideias ou conceitos ou novas associações entre ideias e conceitos pré existentes. ${ }^{4}$ Lebahar apoia-se em John-Laird para pôr em causa

'essa crença ingénua segundo a qual a criação resultaria sistematicamente de associações de ideias não habitualmente associadas. Esse ponto de vista crítico opõe à tese mecanicista da «analogia criativa» o facto de que qualquer criação de uma novidade implica o respeito de certos constrangimentos e a transformação em obra de conhecimentos profundos tal como os processos de elaboração de hipóteses de conceção que nem sempre são instantâneos' (2007, p.89).

15 Para Lebahar (2008), o concetor é o herdeiro do progresso técnico e das suas consequências organizacionais, dependendo as suas realizações das evoluções das situações e da sua própria evolução. Diversas observações levam ao sublinhar a influência da ferramenta e em particular do computador na exploração das possibilidades de soluções alternativas e o controlo das representações intermediárias bem como a influência do conhecimento dos materiais disponíveis para melhor adaptar as diversa possibilidades de artefactos ao encomendado. Se não se considerarem senão 
os extremos poderia dizer-se que se a familiaridade nomeadamente com o computador pode induzir diferentes estratégias de conceção, determinados artistas procuram sobretudo apropriar-se de, e ensaiair, diferentes técnicas para obter os resultados que desejam. Um ponto essencial do processo de conceção persiste: 'uma particular atenção ao controlo dado que algumas das suas inspirações espontânias são susceptíveis de provocar catástrofes» enquanto que 'relações impulsivas, rápidas, fulgurantes, happenings ...' (Lebahar, 1998 p.12) suportam certas correntes artísticas. Um designer com galões não reduzirá demasiado rapidamente a incerteza 'para não ser surpreendido porque os erros custam caro'. A função dos modelos de simulação está mesmo a ser simultaneamente instrumento de representação, de controlo e de regulação da atividade de conceção quer ela seja individual quer coletiva. (Lebahar,1997).

Todavia, esta oposição deve ser matizada: parece que quanto mais nos aproximamos da técnica mais se desenvolvem processos de ajustamento e de auto-controlo na criação artística antes da criação da obra definitiva. Rodin criava as suas estátuas em gesso antes da confeção dos moldes onde era fundido o bronze. Heinrich Khün fazia esboços das suas paisagens e submetia os seus modelos a intermináveis sessões de pose antes de tirar a fotografia. Estudava os gradientes de luz e de luminosidadeexperimentando várias técnicas de impressão.

o termo inventividade que tem uma ressonância mais técnica e científica corresponderia mais à conceção arquitetural e do design que o de creatividade que induz sobretudo a ideia de estética, de arte, ainda que os aspetos estéticos tenham um lugar importante na conceção. 'Um produto que não seja bonito não se compra e um produto funcionalmente perfeito também não se compra se um produto concorrente for mais bonito' dizia um designer que Lebahar observou (1996, p.128), mas para este trata-se mais de 'sedução' que de estética (idem, p.131).

\section{O desenvolvimento de competências em conceção, como equilibração}

Esta caraterização dos processos de conceção faz sobressair a extrema complexidade desta atividade que implica conhecimentos, saberes e saber fazer multidomínios, a pôr em prática em situações operacionais, elas próprias complexas. Os indicadores de competência sobretudo qualitativos, são numerosos e podem ser oriundos quer de observáveis de atividade (qualidade e valor de uso do produto, domínio dos constrangimentos e recursos da envolvente) quer inferidos da observação do desenrolar desta atividade e de entrevistas (conhecimentos, metaconhecimentos, esquemas de ação, etc., modalidades de autoregulação da atividade e de regulação da envolvente profissional) (Lebahar, 1997 b).

De uma maneira geral Lebahar assimila a produção dum modelo de artefacto a uma microgénese. Apoiando-se na teoria da equilibração de Piaget descreve, num quadro construtivista, a elaboração de modelos entre a arte e a técnica para responder aos constrangimentos materiais da situação e elaborar compromissos entre as exigências dos diferentes atores. Na ótica piagetiana que é a sua, 'a abordagem cognitiva do processo de conceção baseia-se na hipótese geral de uma equilibração entre o sistema humano de produção de conhecimentos do designer e a solução do problema de design, a representação final do produto.' (Lebahar, 1993, p.39). A análise da evolução das representações 
intermediárias produzidas pelos arquitetos e os designers com galões permitem a Lebahar mostrar que a sua atividade de equilibração se desdobra em dois mecanismos: constrói soluções que controla, avalia e conserva ou rejeita numa pesquisa construtiva de uma solução sintética, o produto global. Ao mesmo tempo Lebahar insiste sobre o facto que ele age sobre esta construção de soluções, 'a sua solução', para garantir o seu sucesso a despeito de a modificar parcialmente quando o obstáculo em questão é um constrangimento que se mostra incontornável. Este desdobramento cognitivo aparece como uma caraterística essencial da atividade do designer.

Tentando compreender a mais longo prazo a génese da perícia, ele compara a atividade de um desenhador CAO com galões com a de um novato, 'encarregado de estabelecer modelos geométricos simulando as sucessivas hipóteses de um posto de pilotagem'. Apoiando-se sempre a sua hipótese geral na teoria da equilibração faz com que 'a aquisição das capacidades operacionais equivalentes às de um desenhador CAO perito - recuperar as informações, utilizar um domínio de conhecimentos amplo e estruturado, controlar a sua própria atividade - resulta do desenvolvimento da perícia de um novato e das tentativas de controlo que este aplica a esse desenvolvimento' (1997 c). A análise da atividade do desenhador CAO novato põe efetivamente em evidência um relativo desconhecimento dos objetos do domínio, uma organização parcelar dos objetos e dos meios operativos correspondentes, a utilização de traços superficiais aos quais é difícil fazer corresponder significado, dificuldades de passagem do desenho 2D a uma interpretação em 3D, pesquisas pematuras de significado, analogias não forçosamente pertinentes; encontramos aqui numerosas caraterísticas do desenvolvimento de competências profissionais com a experiência, que puderam ser postas em evidência em outros ofícios (Weill-Fassina \& Pastré, 2004).

21 A análise da atividade dos estudantes-concetores em situação pedagógica permitem retroceder ainda mais na génese das competências em design. Nesta etapa, 'a situação permite pôr em evidência indicadores de competência de conceção mas também condutas «de assimilação subjetiva» tal como Piaget a definia (1968). Entender-se-ão por «assimilação subjetiva» as condutas que para um sujeito concetor consistem em adaptar consciente ou inconscientemente, uma tarefa de conceção aos seus próprios objetivos sem que estes não sejam objeto de uma necessária acomodação aos constrangimentos dessa tarefa' (Lebahar 2007, p. 244).

Estas análises muito finas do desenvolvimento das atividades de conceção numa perspetiva micro e macrogenética permitem encarar um ensino do design industrial que não é tanto um ensino da criatividade como uma metodologia da conceção apoiada em múltiplos conhecimentos pluridisciplinares. É este ponto de vista didático que desenvolve na sua última obra L'enseignement du design industriel ${ }^{5}$ aparecida em 2008, dois anos antes do seu falecimento em 2010.

BIBLIOGRAFIA

Lebahar, J.C. (1993) Aspects cognitifs du travail de designer industriel. Design recherche, 3, 39-55. 
Lebahar, J.C. (1996) Séduction. in Dictionnaire international du graphisme et du desigh industriel. Paris: Éditions du Regard.

Lebahar, J.C. (1997 a) La simulation,instrument de représentation et de régulation dans la conception de produit.In P. Béguin et A. Weill-fassina (Eds), La simulation en ergonomie [77-96]. Toulouse: Octares.

Lebahar, J.C.(1997 b) Complexité des compétences de création industrielle: Qui évalue? Quoi? Comment? Connexions, 70, 151-164.

Lebahar, J.C. (1997 c) Genèse d'une expertise: Le cas d'un dessinateur novice destiné à succéder à un expert en simulation CAO. Tapuscrit, 25 pages. Communication personnelle)

Lebahar, J.C. (1998) Christian Jaccard. Montreuil-sous-Bois: Au même titre éditions

Lebahar, J.C. (2007) La conception en design industriel et en architecture. Paris: Hermés, Lavoisier...

Lebahar, J.C. (2008) L'enseignement du Design industriel. Paris: Hermes, Lavoisier,

Piaget, J. (1968) La formation du symbole chez l'enfant. Lausanne: Delachaux et Nestlé.

Weill-Fassina, A. \& Pastré, P. (2004) Les compétences professionnelles et leur développement. In P. Falzon (coord.). Ergonomie, Paris: PUF, 213-231.

\section{NOTAS}

1. Nota do tradutor: 'A conceção em design industrial e em arquitetura'.

2. Nota do tradutor: A descrição sumároa destes jogos pode ser encontrada em https:// pt.wikipedia.org/wiki/Torre_de_Hanói e https://en.wikipedia.org/wiki/ Marienbad_(video_game)

3. Nota do tradutor: traduzida a partir do francês: https://fr.wikipedia.org/wiki/Créativité

4. Nota do tradutor: traduzida a partir do francês: https://fr.wikipedia.org/wiki/Créativité

5. Nota do tradutor: $\mathrm{O}$ ensino do design industrial

\section{NOTAS DE FIM}

i. Nota do tradutor: traduzida a partir do francês: https://fr.wikipedia.org/wiki/Créativité

\section{AUTORES}

\section{ANNIE WEILL-FASSINA}

GRESHTO - CRTD - CNAM

41 Rue Gay-Lussac 75005 Paris France

weill.fassina@orange.fr 